\title{
Organizational Justice in Relation to Competence, Commitment and Self Motivation
}

\author{
Spriha Mukherjee $^{1 *}$, Prof. (Dr). Abha Singh ${ }^{2}$, Dr. Sakshi Mehrotra ${ }^{3}$
}

\section{ABSTRACT}

For the effective functioning of an organization, it is important for its employees to perform effectively. The level of organizational justice perceived by the employees affects their individual level of competence, commitment and self motivation to a great extent. And this in turn affects the employee's level of performance within the organization. Organizational justice are of four types, Distributive relating to distribution of resources, Procedural relates to fair execution of procedures, Interpersonal relates to relationship shared with the co-employees and interpersonal relates to the way things are communicated to the employees. All these types of justices when met in accordance to the need of the employees working within the organization leads to better functioning and productivity. The current study aims to study and analyze the level of Organizational Justice in relation to Competence, Commitment and Self Motivation. It was hypothesis that Organizational Justice will share a significant relationship with Competence, Commitment and Self Motivation. The study reported that there exists a positive and direct relationship between Organizational Justice and Competence, Commitment and Self Motivation. With an increase in the level of organizational justice the level of CCSM will increase and with a decrease in the level of organizational justice the level of CCSM will decrease.

Keywords: Organizational Justice, Competence, Commitment, Self Motivation

Organizational psychology is the scientific study of human behaviour within organization and about the various psychological theories that can be applied for its betterment. The application of theories of organizational psychology can be seen in all branches of an organization functioning at it's best for constant enhancement in the level of prosperity. But here we shall talk about the importance of the role played by organizational psychology in relation to the level of justice prevailing and its effects on the performance of the employees. Organizational psychology is that branch of psychology which deals with employee behaviour and well being, resulting in overall

\footnotetext{
${ }^{1}$ MAAP batch 2013 - 2015, AIPS, AUUP, Noida, India

${ }^{2}$ Director AIPS, Supervisor for Dissertation, India

${ }^{3}$ AIPS, Co-Supervisor for Dissertation, India

*Responding Author

(C) 2016 I S Mukherjee, A Singh, S Mehrotra; licensee IJIP. This is an Open Access Research distributed under the terms of the Creative Commons Attribution License (http://creativecommons.org/licenses/by/2.0), which permits unrestricted use, distribution, and reproduction in any Medium, provided the original work is properly cited.
} 


\section{Organizational Justice in Relation to Competence, Commitment and Self Motivation}

organizational prosperity. It focuses on various aspects of employee wellbeing and behaviour. In recent times it has been seen that organizational justice has come out to be a relevant factor among those affecting the work attitude of employees. Most dominantly it affects the level of work commitment, competence and self motivation of an employee.

Organizational justice was first postulated in the year 1987 by Greenburg. It refers to how an employee perceives an organization's actions, decisions and behaviour and how this pattern of perception ultimately affects the behaviour and attitude of the employee in the long run. Organizational justice relates to how an employee judges the behaviour of an organization and the employee's resulting attitude and behaviour. How well an employee percieves the justice prevailing within the organization depends on various factors such as:

- fair treatment,

- healthy work environment,

- basic pay schemes,

- recognition of efforts,

- availability of prerequisites,

- reinforcements etc.

These factors directly affects three main variables namely, work commitment, competence and self motivation. For any organization to work effectively it is mandatory to comply with the basic justice needs of an employee. This results in increasing the level of job satisfaction among the employees to great extent, thereby contributing in high rates in the overall productivity of an organization.

In today's senario where exists cut-throat competition among various organizations especially when it comes to how well do they manage and function, organizational justice turns out to be a major factor of analysis. Those organizations which makes sure that the level of justice prevailing is fair gains more economic stability as compared to those which is not able to maintain such fair levels of justice. Employees get attracted more towards such organizations which takes into consideration even the smallest of elements which acts as a recognition to their basic requirements or needs. They feel comfortable and encouraged to put in their efforts into such organizations.

While understanding and managing organization behavior, among the various elements that are taken into consideration, organizational justice should exist among the priorities. The level of prevailing justice not only and its complete analysis in depth would help in not only understanding the functioning of the organization from an employee's point of view, but also will throw light on the level of effective functioning capabilities of the managing team. The concept of Organizational Justice has emerged from the Equity Theory, given by Adams 1963 and 1965. The theory explains how the judgments on both equity and inequity can be derived from the comparisons made between one self and all others based on the various inputs and outputs. Inputs refer to the level of knowledge or efforts of an individual while outcomes comprises of 


\section{Organizational Justice in Relation to Competence, Commitment and Self Motivation}

recognition, pays and perks. Organizational justices are of four basic types namely; Distributive, Procedural, Informational and Interpersonal Justice.

Distributive Justice: Refers to the equal distribution of resources in an organization. It relates to the fairness that prevails in the distribution of resources, both tangible and intangible. Tangible resources refer to pay schemes and bonuses whereas intangible resources refer to the appreciation or praise received for one's efforts.

Example: The employees of any particular organization would feel content about the level of justice prevailing within the organization only if he/she finds that there has been fair distribution of salary packages in accordance to the posts, distribution of perks and bonuses have been fairly done etc.

Procedural justice: It refers to the level of justice that prevails during various organizational processes. The employees perceive this justice according to the extent to which they hold a say in the decision making and processing of an organization. They should be made aware of the accuracy, authenticity and validity of the processes that has been decided to put into execution for achieving desired results.

Example: For any employee the level of perception of organizational justice would be high if he/she feels the right to have a say in the important decision making process of the organization, like in terms of planning and execution of procedures of any major changes thought of by the company.

Informational justice: It relates to the degree to which employees are provided information regarding various activities and procedures of an organization. It is positively perceived by the employees when they are appropriately informed about the various informations that relates to the functioning of an organization.

Example: When an employee is well informed about both major as well as minor informations that are mandatory for him/her to be aware off. Communication chain thus within an organization calls for an effective smooth processing, avoiding any confusions or complexities.

Interpersonal justice: It defines the justice perceived by the employees on the basis of the treatment that they receive, approach their higher authorities and third parties have towards them. It requires the authorities to appropriate their employees in a polite, dignified, and respectful manner.

Example: When an employee enjoys the kind of work environment he is being provided with, wherein he can interact, discuss and communicate things with both his higher officials as well as subordinates with least of inconvenience and awkwardness. 


\section{Organizational Justice in Relation to Competence, Commitment and Self Motivation}

Organizational justice holds immense importance in all forms for effective functioning of any organization. In all stages and phases it determines the level of performance of the people working within the organization. For constant assurance of better quality of performance on part of those working in an organization the level of level and quality of justice has to be assured constantly. Few importance of organizational justice are listed as following:

- Increased organizational citizenship behavior

- Increased level of contribution on part of the employees

- Increased level job satisfaction

- Increased level of organization productivity

- Increased level of organizational goodwill

- Increased level of innovation among employees

- Smooth functioning of the organization

- Least amount of organizational conflicts

- Better decision making processes.

Thus organizational justice is said to be a multidimensional construct comprising of four different types of justice. It derives its roots from the Equity Theory of Adam, in year 19631965. This theory explains that the judgment of equity and inequity is derived from the comparison done between oneself and others based on inputs and outcomes. Input refers to what an employee is perceives to be contributed in organizational productivity and outcomes refers to what an employee perceives to receive as a result of his/her contributions.

For effective and efficient working of an organization, it is important to comply by these four types of justice to the right extent. Especially if an organization is willing to enhance the level of commitment, competence and self motivation among its employees, for attaining better developmental results.

Work Commitment refers to the extent to which an employee is willing to put in his utmost efforts, making best use of his potential, with an aim to contribute best results in organization's productivity. An employee feels committed towards work when he feels that his efforts are being recognized or when he is fairly awarded his dedicated performance.

Competence refers to an employee's confident approach towards overall betterment, by having faith on his existing capabilities, and making all possible efforts to enhance one's performance level with a positive spirit. Competence of an employee guarantees the level of efficiency he is likely to possess and the level of contribution he is likely to make in the process of productivity.

Self motivation refers to the triggering emotion that acts as a constant resource that helps an employee to keep putting in his best efforts for desire results, come what may. These motivational factors are required to be positive, realistic and have a long lasting effect, so that it 


\section{Organizational Justice in Relation to Competence, Commitment and Self Motivation}

may help in making an employee feel positively attached to his work tasks and work environment.

There exists a direct relationship between Organizational Justice and Work Commitment, Competence and Self Motivation. It is well observed and understood that; higher the level of justice in an organization, higher will be the level of work commitment, competence and motivation among the employees.

There are various factors that affect the relationship of organizational justice with that to the level of work commitment, competence and self motivation. Higher the discrepancies among these factors, more adversely will the relationship between both be affected. Hence the given treatise aims to study and analyze how a better balance between both organizational justice in relation to work commitment, competence and self motivation can be maintained for effective functioning of an organization.

This study has been done with an aim to throw lights on the upcoming demand in the field of organizational psychology of organizational justice, as it is immensely important for the effective functioning of the organization. With rising level of work pressure and requirements, it has become mandatory to work upon the components that contribute to the overall efficiency of an organization. However, commitment, competence and motivation being the important ones. These three variables form an integral part of the work efficiency level of the employees. It gives an idea as to how well an employee is to perform in terms of commitment, competence and self motivation, when his organizational justice needs are taken good care off.

Every organization desires its employees to be fully functioning. A fully functioning employee is one who is completely aware of his or her potential level and is ready to make contributions in the growth and prosperity of the organization with willingness. He is considered to have achieved successfully all stages of Hierarchy of needs, as explained by Maslow. Maslow's theory of hierarchy of needs comprises of five stages:

- Basic needs: Food, clothes, shelter, emotional needs etc.

- Security needs: Assurances of the safety of all his basic needs.

- Social needs: The need to socialize with people and create connections based on his capabilit ies

- Esteem needs: Recognition of his efforts, capabilities, potential, knowledge etc.

- Selfactualizationn: The final stage where an employee is well aware of his level of potential and is willing to make the best use of it for better results.

For any individual there are set of Basic Needs that needs to be fulfilled for him/her to feel motivated to achieve further in life. These basic needs comprise of the basic survival requirements of any individual like food, shelter, clothing, relationships, job etc. Only when these needs are fulfilled does an individual feels motivated to work and achieve more. 


\section{Organizational Justice in Relation to Competence, Commitment and Self Motivation}

Next level calls for the demand of security on part on the individual for the basic needs that he has acquired, like he/she would expect the job acquired to be stable one and not fluctuate in terms of income and facilities so that further future goals can set and worked upon with ease.

Once an individual is sure and feels confident that his/her security needs are well met, the next motivation requires for him or her to socialize with people, connect with them and strengthen the existing healthy bonds.

Next comes the motivation to attain recognition for the efforts made and success achieved. An individual desires for an appreciation for the level of capabilities and potential that he/she holds. These appreciations or recognitions add on to the level of motivation for an individual to aim higher.

The final level comprises of self actualization wherein an individual is well aware of his/her level of potential and performs accordingly. A self actualized individual is well satisfied with his accomplishments and is equally motivated to work and achieve better ahead.

Organizational justice is considered to be a part of the fourth stage that is, the stage of fulfillment of Esteem Needs. It's just the previous stage of self actualization, and once and employee is observed to have successfully achieved the esteem stage, an assurance for him to become actualized and thus performing even better develops.

But just successfully accomplishing these stages wouldn't add on to the maintenance of wellbeing of an employee. This is where constant efforts to maintain and enhance organizational justice level would be required. This process is not just a onetime project, but a long term aspect of successful functioning of an organization. With new employees coming in and old employees getting retired, the organizations will have to constantly work on the assessment, evaluation and enhancement of the justice level prevailing. We can say that commitment towards work, competency and self motivation are like an asset to the employee and employees are an asset to the organizations.

Thus for better functioning of any organization, it has to work upon the maintenance of its asset, with organizational justice helping them to protect their asset against any liability.

Work commitment refers to the sense of responsibility held by an individual towards his work and organizational tasks given to him. Commitment level varies from person to person depending on various factors such as job satisfaction, self confidence, self actualization etc. Commitment can be understood in other words as an individual's willingness to contribute the best of his or her efforts to successfully accomplish any task whose responsibility has been vested upon him. Work commitment holds a direct relationship with organizational justice as any change in the latter would result in affecting the former. Organizational justice when positively perceived by an employee of any particular organization makes him/her feel content about his job from an overall perspective and this results in making him/her contribute more efforts and better determination towards his goals and come up with much better results. 


\section{Organizational Justice in Relation to Competence, Commitment and Self Motivation}

Work commitment is of three types namely, Affective Commitment, Continuance Commitment and Normative Commitment. These three types of commitment are explained as follows:

Affective Commitment: refers to what extent do you feel emotionally attached to the organization and the work that you perform over there. This relates to the extent to which you feel yourself emotionally connected to your current job and how important it is in your life in terms of your feelings.

Continuance Commitment: refers to how willing your are to continue working with the current organization. It relates to how do you think about continuing to working with the present organization and how will it affect you if you stop working with it.

Normative Commitment: refers to how obliged do you feel towards your organization and how well does this feeling of being obliged helps you to feel connected with the organization and keep working with it.

Importance of work commitment can be understood by the following given points:
a. Better work quality
b. Better creativity in work contributed by the employees
c. Existence of better focus and interest level in work on part of the employees
d. Better management of work pressure
e. Least tendencies to complain about work
f. On time completion of work and many more.

Competence is commonly known as the ability to perform something successfully or efficiently. In other words we can say that competence relates to the affectivity of an individual to put in the best of his efforts in the accomplishment of any task that has been assigned to them. Competence of an individual varies depending upon the capabilities and potential that he holds and more importantly on the fact of how he or she perceives oneself to be able enough to perform any task that has been assigned. Competence in the first place calls for the sense of responsibility and its link with one's capabilities. Only when an individual realizes the responsibility that he/she has been vested with will he or she make use the existing competencies in order to achieve the desired results.

Competence is also directly related to organizational justice. With an increase in the level of organizational justice the level of competence among the employees is believed to get increased. Reason being, with an increased and satisfied level of prevailing justice, any employee would feel content and will find it promising enough to put in his efforts for deriving required success.

Few importance of competence can be listed as follows :

a. Better concentration level and focus sc on work

b. Better contributions to organization's productivity.

c. Better sense of work related responsibilities 
d. Increased level of determination to achieve the desired results.

e. Satisfactory level of output obtained from employee's being efforts put in

Self Motivation can be understood as the ability or rather willingness to perform any task. The true meaning of these words lies within these words itself that is, an influential source surviving within an individual providing constant encouragement to an individual for performing better and better. Self Motivation holds immense power in enhancing an individual's performance level. Self Motivation is directly related to organizational justice, only when an employee feels content with the level of justice that exists within an organization, will he or she feel motivated to perform better. Every individual is capable enough for performing tasks related to particular field; self motivation is what acts as an influencing source of power to make any individual keep on with the hard work.

Some importance of self motivation can be listed as below:
a. Increased level of interest in work area
b. Better performance ability
c. Better focus on work
d. Continuity in hard work
e. Enhancement in level of creativity
f. Enhancement in level of innovation

Organizational Justice in relation to work commitment, competence and self motivation calls for the study of how the level of prevailing justice affects the level of work commitment, competence and self motivation among individual employees. Organizational justice is believed to share a direct relationship with work commitment, competence and self motivation, with an increase in the level of justice the level of other three variables taken into consideration increases and with a decrease in the level of justice the level of other three variables decreases. Measuring organizational justice requires the study, calculation and analysis of the three sub components of justice namely, distributive, procedural and interactional, which are in turning measured together through one scale. The three variables namely commitment, competence and self motivation are analyzed by one individual tool. The results of both the tools are compared and analyzed for better understanding of the relationship existing between organizational justice and the three variables

Previous studies when analyzed showed that distributive and procedural justices have more influence on the level of work commitment and competence while interactional justice had more influence on the level of self motivation. Reason being that resources when distributed evenly and processes when carried out fairly makes an individual feel more content and satisfied therefore inculcates a sense of commitment and competence among individuals regarding their work. When the working environment is friendly and cooperative then it leads to an increase in the level of Interactional justice. 


\section{Organizational Justice in Relation to Competence, Commitment and Self Motivation}

For improving the level of prevailing justice within an organization there are various factors that are needed to be taken care off such as basic resources should be distributed evenly among all employees despite of their positions that they hold within the organization. These resources consist of basic work environment facilities, medical aids, hygiene facilities etc. Next comes the sway of each and every concerned employee in the working and functioning of a particular area. Such concerns regarding an employee's point of view and opinion creates a sense of recognition among the employees.

For their even minor efforts to be recognized the employees expect the organization to make an initiative to know how they are working and in what ways are they satisfied with the way organization is working. In such ways the employees feel that their opinions and expressivity is well respected and looked upon to understand their overall level of work environment wellbeing. Any changes or enhancement made in the existing procedures of an organization has to involve the right to place one's opinion, view or say on part of the employees.

The work environment plays a significant role in the overall performance of an employee within an organization. Employees expect their working environment to be friendly, cooperative, free from biases and motivating. In order to make sure that an employee is satisfied with his or her working surroundings the organization has to make sure that the type of people working together in any given particular environment are sharing a common base to interact, bond and work on healthy terms.

Also the various information travelling through various channels of communication should be well conveyed to all the concerned people without any biases involved. This ensures a fair level of interactional justice to prevail within the organization. The channels of communication have to be direct so that minimum level of conflict and communication gap exists among the various departments.

Studies on organizational justice has been done since a long time and in relation to work commitment, competence and self motivation at an individual level as well, but in relation to work commitment, competence and self motivation together is comparatively a new aspect taken into consideration for studying. This study is expected to expand the scope of further studies to be done in the field of organizational justice and its role on the overall development of skills among employees that ultimately results in the enhancement of quality of work performance of an employee. Such studies will help concepts like organizational justice's role in the overall development and maintenance of organizational wellbeing to gain grounds in the near future. New understanding of organizational functioning patterns will come into existence and promote interest of people in this given field for conducting further such researches.

Dealing with the day to day requirements of any organization is a huge task in itself and it is not that easy for any organization to shoulder such a responsibility with complete ease. There are various hassles which they usually have to deal with expertise. In such situations fair level of organization justice prevailing within the organization acts as an advantage to the organization's 


\section{Organizational Justice in Relation to Competence, Commitment and Self Motivation}

rescue. Fair level of organizational justice leading to better level of commitment, competence and self motivation among employees assures a sense of responsibility and enhanced level of organizational citizenship behavior among them. Thus resolution of such crisis becomes easier with more employees willing to contribute towards it.

Researches done by Li and Cropanzano in the year 2009 showed that an individual's level of perception of organizational justice is often influenced by a group or team's opinion. This form of justice perception is called "justice climate". Here an individual employee perceives the kind of justice prevailing within the organization in accordance to the ways in which his other team members perceive and understand it. Hence the organization has to primarily work for an entire group and not just for employees at an individual level.

Organizational justice is not only responsible for internal effective functioning but also for the organization's relationship with other companies and over all market. Other companies would any day like to affiliate with such an organization which maintains high and fair level of justice as it assures that the organization can be relied upon. This in turn affects the market goodwill of the concerned organization. And any organization having a better goodwill in the market can think of expanding their business in order to create more and better opportunities for its employees. This in turn again contributes to the act of maintaining organizational justice.

The primary responsibility of keeping a check over the level of organizational justice prevailing within the organization is that of the training and development department. The training and development process comprises of a cycle wherein the first step is of observation, followed by analysis then implementation and finally follow up The prevailing Organizational justice has to be first observed, then an analysis of how it can be enhanced more is done, followed by creation of required plans and finally implementation of these plans are done followed by follow ups as to what extent the process has been successfully executed.

It is a long term process and cannot be considered a short term phenomenon or situational demand. For the long term effective operation of organizational functions the level of justice needs to be kept intact with minimum hassles involved in it. Organizational justice requires the effort of every single individual working within the company to maintain it at desirable levels. Where on one hand the company is expected to be fair with its policies and treatment, there on the other hand the employees are expected to be honest with their level of perceptions. One has got no rights to blame and create professional inconveniences for the organization for their own personal dissatisfaction arising from personal unsorted issues. For such employees the organizations are recommended to hire counselors who can work on the wellbeing of the employees from time to time even at a personal level. This way the organization will be able ensure biases free feedbacks and recommendations from their employees.

Since organizational justice comprises of factors affecting the performance of an individual at an individual level as well, hence its positive correlation with Commitment, 


\section{Organizational Justice in Relation to Competence, Commitment and Self Motivation}

Competence and Self Motivation can be well expected. Any infractions or other conflicts within the organization creates high chances for the employees to stand against the organization for the sake of personal defense, but organizations with better justice levels prevailing within can ensure better support and understanding on part of the employees for themselves. Such organizations with higher level of justice existing will be successful in inculcating high level of commitment, competence and self motivation among its employees also adding onto their organizational citizenship behavior as well.

This over the long run works as huge benefits for both the employees as well as organizations. More effective performance will be rendered by these employees getting to experience more in the work field and working accordingly with an aim to produce better results and thus they'll get rewarded for the same from time to time. Also the organization will have spent minimum cost over rectification of procedures affecting the overall functioning of the organization. We can put it this way that it would be a profitable and cost effective venture in the long run.

\section{REVIEW OF LITERATURE:}

Robert. H.Moorman, Brain.P.Neihoff and Deniss.W.Organ ( 1993) found for controlling the effects of job satisfaction and organizational commitment, there was a relative contribution of perceptions of procedural justice towards predicting organizational citizenship behavior. The study was done to know the organizational citizenship behavior and the way employees are treated in an organization. They also studied how issues relating to procedural justice, job satisfaction and organizational justice was sorted and in what ways. It was found that employees with higher realization of organizational justice in an organization felt more satisfied with their job and in turn showed more commitment towards their work.

Lowe, Stephen and Vodanovich (1995), found that distributive and procedural justices are strong predictors of level of work commitment in an organization. They have suggested for distributive and procedural justices to be studied separately in order to understand their long term affect on the overall performance of an employee. This way measures to enhance the level of work commitment can be brought about in more appreciable manner.

Martin and Bennett ( 1996), found that justice judgments are central to the development of commitment and satisfaction. They suggested that "global evaluated system", leaders and institutions are closely related to procedural justice; on the other hand evaluation of "specific" personally relevant outcome is related to distributive justice. Results showed that satisfaction and commitment are independent when role of justice was taken into consideration.

R.Ficher, ( 1997),found that work commitment and motivation is directly related to distributive justice. When an employee is awarded for his or her efforts, he feels all the more motivated to perform better in his tasks, and this motivation turns into commitment towards his work. Distributive and Procedural Justice needs to be enhanced in order to inculcate high level of work commitment and self motivation among employees. 


\section{Organizational Justice in Relation to Competence, Commitment and Self Motivation}

Tremblay, Sire and Balkin, ( 2000), found that distributive justice perceptions are better predictors of pay satisfaction as compared to procedural justice perceptions. The employees clearly distinguish between the benefit satisfaction and pay satisfaction. But in case of benefit satisfaction, we get to observe that procedural justice perceptions are better predictors than distributive justice perceptions. Finally results showed that with regard to pay, distributive justice play more important role compared to procedural justice in satisfaction of the organization as well as job satisfaction of the employees. Hence the level of commitment towards work is more in case of distributive justice perceptions.

Lemons and Jones (2001), found that procedural justice plays and important role in determining the level of work commitment among employees. Procedural justice relates to the various decision making processes that existed within the organization which influences their level of perception of organizational justice to great extent.

Rhoades et.al. (2001), found that there exists a positive association between organizational rewards, organizational support, justice and work commitment. With an increase in the level of perceived organizational support and justice, it assures favorable work conditions and hence the level of affective work commitment increases.

Yoon and Thy (2002), found that organizational justice is perceived better by the employees working in the organization, when they perceive organizational support and job satisfaction to maximum extent. And this ultimately leads to better performance of employees at work resulting from better level of work commitment. In other words we can say that work commitment can make to exist as an important quality among employees by catering to their needs for organizational justice.

Sussana Baldwin, ( 2006), found that the principle of organizational justice is not complex to apply on the whole and is supposed to be considered more than social technology in the vein of sound managerial practice. There are always chances in existence for some interventions to be less successful in some context, but none leaves scope for it to be harmful, but what least it will do is promoting a sense that organization is concerned about its fair policies. These policies when implemented well will help in making significant contribution in making performance better in the organization, preserving employee dignity, improving their level of work commitment and promoting a sense of humanity among them.

Lambert, Hogan and Griffin,( 2007), found that both procedural and distributive justice cause an impact over the organizational work commitment level of an employee. The perception of distributive and procedural justice on part of an employee depends upon the fairness with which the resources are distributed, the both tangible (in terms of money) as well ad intangible ( in terms of praises and appreciation), the accuracy of the information conveyed, manner in which processes are carried out etc. 


\section{Organizational Justice in Relation to Competence, Commitment and Self Motivation}

Martha.C.Andrew, K. Michele Kacmar, Gerald .L. Blakely and Neil. S. Bucklew, (2008), found the relationship between the four dimensions of organizational justice and organizational commitment. Results indicated that relationship between interpersonal, distributive and informational justice and affective commitment was stronger in case of those individuals who reported to have high level of work group cohesion. But relationship between affective commitment and procedural justice stayed unaffected through work group cohesion.

Bakshi, Kumar and Rani, ( 2009),found the relationship between perceived organizational justice, job satisfaction and work commitment. The results showed the perceived organizational justice plays a crucial role in development of organizational commitment and job satisfaction. This study aims to provide the policy makers as well as administrators an insight into the relationship between organizational justice and work attitude of the employees. Also an insight into how employees can be managed by using organizational justice perceptions, resulting into positive work environment. It was found that people who perceived more of organizational justice showed more job satisfaction as well as commitment towards work.

Klendaur and Deller (2009), found that interactional justice plays a crucial role in determining the level of work commitment in an organization. Instrumental evaluation and trust can work as mediators for developing positive correlation between organizational justice and affective work commitment.

Irfan and Gokee, ( 2009), found that it essential for the managers to be just with the distribution of financial earnings and with the procedures related to these earnings, also should work upon existence of better interaction between the managers and the employees. They found that the perception towards organizational justice did not vary according to the gender. Highest organizational commitment level is seen in elementary educational level, and lowest organizational commitment is seen in college educational level. Hence we can say that interactional and relationship based justice do influence the work commitment levels.

Elaine Farndale, (2010), found the importance of trust and justice in an organization for achieving desired outcomes from the performances. As quoted by Folger and Konovsky in 1989,conclude: "to be maximally effective in sustaining employee commitment to an organization and trust in its management, those making allocate decisions must take procedural justice into account”. Their findings redefined the statement emphasizing the moderating role of trust in achieving perception of justice and employee commitment as well as emphasizing the crucial role played by the three categories of justice. The main aim is to find ways of solving discretionary behavior in management and employees, for stimulating organizational commitment in them. Their findings suggested that through ensuring that line management are capable of carrying HCPM practices, resulting in increased focus on improving perception of justice, during required changes it helps in improving level of work commitment.

Ponnu and Chuah (2010), found that organizational justice plays a significant role in the enhancement of level of commitment towards work among the employees. Organizational justice 


\section{Organizational Justice in Relation to Competence, Commitment and Self Motivation}

when prevails at a fair and expected rate assures the employees a better functioning of the organization and thus they decide to put in better level of input on their part.

Thorn, (2010), found that procedural and interactional justices are directly and positively related to organizational commitment. With development in the level of procedural and interactional justice, the level of job satisfaction among the employees was found to increase as well. Components such as decision making, planning and information conveyed affect work commitment levels, which leads to job satisfaction ultimately.

Muhammad Jawad,Sobia Raja,Aneela Abraiz, Tahira Malik Tabassum,COMSAT Institute of technology,Wah Cantt,(2012), found that; for several years organizational justice has been a crucial topic on the discussion board, Human Resource Management, Organizational behavior and Organizational Psychology(Cropanzano 1997);(Colquitt 2001); (Greenberg’s 1990). Various kinds of justices has been taken into consideration for a longer period of time.(Deutsch.M 1975); (Adams 1965); Organizational Justice basically deals in explaining the level of fairness that exists in an organization, based on the observation made on the kind of treatment received by the employees as well as their perceptions on both individual and group level.(Detsch.M 1975;k.1993);(Greenberg.J 1990). Organizational justice is regarded to be the top most among the organizational behaviors. Reason being there exists a direct relationship between organizational justice and its outcomes. (Folger R.;Konovsky1989). Organizational justice leads to organizational commitment as well as supervision commitment.

Ghorbanalizadeh,Safania and Tayabi, (2012 ),found that the most crucial role that any organization plays is to practice and maintain an organizational environment, where an employee would get to feel justice and in turn a positive effect would be seen in their work attitudes, such as commitment, job satisfaction etc. Their study indicated that, although overall organizational justice plays a significant role on overall organizational commitment, but procedural justice was found to have a better impact on the overall job satisfaction, on the other hand distributive justice has an impact on the overall organizational affective commitment. They stated that only by understanding each of the dimensions of the organizational justice which its effect on the work attitude of an employee, is how we'll get a better understanding of various justice angles and how it influences.

Neha Kumari and Nishant Affroz,( 2013), found that organizational justice impacts creative work behavior in terms of both procedural and distributive justice components. On the other hand, it is revealed by the psychological contracts that work place behavior in an organization is influenced by an employee's perspective, such as fulfillment of mutual contractual obligations. Thus integration was done of organizational justice and psychological attachment for predicting creative work behavior. When studied the relationship between employee creativity behavior and work commitment, it was found that higher job satisfaction lead to higher commitment, ultimately leading to higher creativity. Thus, better integration between individual level creativity and organizational goals were observed in case of employees with high connection, 


\section{Organizational Justice in Relation to Competence, Commitment and Self Motivation}

and highest capability in form of individual level of creativity, leading to highest level of commitment contributes to the organizational development to great extent.

Fariba Rafei-Dehkordi, Sardar Mohammadi2 and Mozafar Yektayar3 , (2013),found that It can be concluded that, like all other previous studies that have been done also shows that with lack of injustice in an organization leads to decrease in the level of commitment in work as well as reduces the level of job satisfaction. The result indicates a direct relationship between organization justice, commitment and its various dimensions. The directors of the organization have to be sure of the existing level of justice in an organization in order to prevent maximum conflicts within the organization. Due to the dependence of effectiveness and efficacy of organization's performance on the effectiveness and efficacy of the employees, it is highly recommended for an organization to look after the fairness, commitment and job satisfaction of employees. Especially in case of distribution of profits, rewards, promotions, sponsorships etc.

Ayobami and Oneyma, (2013), found that there existed a significant relationship between distributive organizational justice and organizational commitment. The perception of employees towards justice was based on the kind of treatment, facilities and behavior they were provided with. With higher level of understanding of employee needs, and by taking initiatives concerned with their needs, and organization is able to provide high level of perceived organizational justice, leading to higher work commitment.

Rai, ( 2013), found that distributive justice falls in direct relation to job satisfaction, organizational commitment and turnover intentions. While work commitment falls in direct relation to procedural justice. Informational justice showed a direct relationship with job satisfaction level. Interpersonal justice was related to no direct organizational behavior. Results showed that in order to enhance organizational work commitment as well as job satisfaction, the organizations are required to pay attention to the kind of leadership styles it promotes, and maintain fairness for encouragement.

Mohemad, (2013), found that organizational justice was the extent to which the employees were found to positively perceive interactions, information, procedures and outcomes. Results showed that there existed a positive correlation between Components of Organizational Justice and Quality performance among different categories of health workers. In order to achieve better generalized results, it was recommended to replicate the study on a larger probability sample from various other hospital settings. With high level of procedural justice, higher work commitment was seen among the workers.

Totawar and Nambudiri, ( 2014) ,found that all four factors of justice i.e. procedural, distributive, informational and interpersonal; should be simultaneously examined and their outcome on work should be noted well. They found through their meta-analysis that satisfaction and commitment was predicted by all four types of justice. Their meta-analysis suggested a causal research to be done on the relationship existing between, fairness, emotions, perceptions and work attitudes. According to them all these act as a contributing factor in the development 


\section{Organizational Justice in Relation to Competence, Commitment and Self Motivation}

and enhancement of organizational justice, leading to work commitment and job satisfaction in any particular organization.

Reimann, (1982), found that organizational justice is positively and directly linked to the competence or effectiveness of an organization. The executives found organizational effectiveness is an excellent predictor of its survival and growth. Besides financial predictors such as revenue and profit growth, several non-financial predictors are also responsible for the continuous overall growth of an organization, competence being one of those non-financial factors. And organizational justice acts as a stimulating factor in this process.

Jung Lee, (2004), found that when employees strongly identify with the organization, their trust is positively related to their competence level. In case of individuals who have weak organizational identification, their organizational trust is not positively linked with continuous improvements. In fact in such cases ultimately the continuous employee improvement level also goes down. Hence managerial implications play an important role in maintaining a positive relationship between organizational trust and employee's identification with the organization, so that the continuous improvement level is maintained.

Kang.D, (2007),found that judgments of justice leading employee training motivation to arise, can be an asset on part of the business for gaining against its rivals a sustained competitive advantage. For the purpose of examining employee's motivation to participate in training activities, this study focuses on three types of justice perceptions; distributive, procedural and interactional. An employee looks forward towards training participation benefits, which in turn acts as a motivating factor for making the employees engage in training participating activities. As a result an increase in their level of competence is also observed.

Tang, Li-Ping, Baldwin and Linda.J , (1996), found the it was distributive justice which was directly related to satisfaction with promotion, pay, commitment and performance appraisal, whereas procedural justice was related to satisfaction with performance appraisal, commitment, supervision and job involvement. Researchers believe that an organization should practice fair treatment towards its employees and should reward them as well based on their performances. Such measures would make the employees have a positive perception of procedural and distributive justice, leading to job satisfaction, work commitment, better competence level as well as increase in the level of self motivation.

Cropanzano and Rupp, ( 2003), found, that existence of fair treatment in an organization leads to the exhibition of higher level of job satisfaction and organizational citizenship behavior on part of the employees, also making them engage less in conflicts and counterproductive activities. Along with this organizational justice promotes a feeling of self motivation among the employees, which is said to predict and direct energies towards positive work behaviors. Interactional justice can be considered as a promotional factor for the development of self motivation among employees. They further divided interactional justice into two parts namely; 


\section{Organizational Justice in Relation to Competence, Commitment and Self Motivation}

informational justice which relates to presence of social accounts and explanations and Interpersonal justice which relates to presence of dignity and respect that one gets to receive.

Kuvaas, (2006), found that it was the base pay level and not bonus pay level which was directly and positively related with level of self motivation and commitment among the employees. Appropriate base pay level is considered to be one of the elements of organizational justice. Further studies showed that the level of motivation and work commitment was not affected by any type of pay plan. There has been observed better level of job satisfaction in cases of better base pay plans as compared to bonus pay plans. Bonus pay plans do act as a motivational force but base pay plan ensures job satisfaction and better commitment towards work.

Phelan, Colquitt, Scott and Livingston, (2008), found that in any organization, employee's self motivation acts as a mediator between the relationship of justice and their task performance. It was observed that procedural justice leads to higher level of self motivation. The results further showed that procedural justice predicted both free choice and self reported measures of motivation. In contrast their study showed that interpersonal justice was not correlating with self motivation, instead its procedural justice.

Phalon, Jason and Livingston (2009), found that procedural justice and interpersonal justice plays a significant role in determining the level of self motivation among employees. The level of self motivation in turn acts as a mediator between organizational justice perception levels and task performance of an individual.

Fatt, Khin and Heng, (2010), found that the higher the level of perception of justice on part of the employees in an organization, higher is their level of job satisfaction and work commitment. In this study both procedural as well as distributive types of justice has been taken into consideration. Therefore organizations which takes proactive approach towards employee's perception of both distributive and procedural justice, has been observed to reap better benefits as there has been higher level of job satisfaction, competence and commitment among employees under such work environment. Positive aspects are observed in employee behavior and their efficiency.

Choudhury, Philip and Kumar, ( 2011), found that employees of any organization can be regarded as its asset, as the entire effectiveness of the organization depends on its employee's skills, expertise, competencies and proactive behaviors, perception of justice being a part of it. Hence it is required for an organization to develop and maintain apt organizational justice policies, so that their may be better perception of justice on part of the employees. And thus therefore would be an increase in the level of their expertise, competency, motivation, satisfaction as well as commitment.

Fall and Roussel, (2013), found that compensation plays an important factor of motivation towards efforts and performance. This compensation may be in the form of incentives as a part of employee's work recognition. In fact comparisons when done between intrinsic motivational 


\section{Organizational Justice in Relation to Competence, Commitment and Self Motivation}

research and self motivational research, it was observed that contribution of self motivation made it possible to explore the new studies relating to the motivational power of compensation. The self motivational theory makes way for better understanding of relationship between motivation and compensation. Hence better level of motivation is observed when there were better provisions for compensations.

Dekhordi, Mohommadi and Yektayar, (2013), found that organizational justice is directly and positively related to job satisfaction, performance appraisal, work commitment, motivation and organizational behaviors. Their findings showed that all four types of justice, namely, procedural, distributive, interactional as well as emotional are directly related to job satisfaction, employee competency, employee motivation and work commitment. Thus every organization should practice organizational justice and should see into issues or conflicts that require their prior attention for better level of satisfaction, commitment and competency arising from motivation.

Raza, Adnan Rana, Mansood Rana, (2013), found that employees will be more committed towards their organization only when there will be fair use of distributive and procedural justice. It was found that employees feel more motivated when they are rewarded and promoted using fair means. It has been observed through the studies that both procedural and distributive justice relates positively with the three construct of organizational commitment, that is exchange commitment, affiliation and identification. More the organizational commitment more is the level of productivity, and hence the progress of the organization is assured.

Gim and Desa, (2014), found that when distributive and procedural justices are perceived to be fair on part of the employees, they tend to be more committed towards their work. It also increases their level of motivation and job satisfaction. Results predicted that both procedural and distributive justice relate positively to commitment.

\section{METHODOLOGY:}

Aim

The current study analysis aims to understand how organizational justice correlates with work commitment, competence and self motivation of an employee. The study has been done with an objective to observe, analyze and understand the extent and ways in how an employee's level if commitment, competence and self motivation is both related as well as affected through changes in the level of Organizational Justice. Primarily the study focuses on how the enhancement of Organizational Justice leads to an increase in the level of work commitment, competence and self motivation of an employee.

Already various studies has been conducted on what leads to organizational justice or employee job satisfaction, resulting in overall development of organizational productivity, thus this study aims to know understand and explain how organizational justice is relating to work commitment, competence and self motivation, which forms an integral part of employee's performance appraisal, that promotes organizational efficiency and wellbeing. 


\section{Organizational Justice in Relation to Competence, Commitment and Self Motivation}

The current dissertation comprises of analysis of data that has been collected with an aim to study the correlation existing between Organizational Justice with work commitment, competence and self motivation. It comprises of a brief understanding of the concept of work commitment, competence level and self motivation level of an employee, and the type of Organizational Justice that creates an impact on it. We get to see a multidimensional construct of Organizational Justice and its affect on the variables taken in this study namely, work commitment, competence and self motivation.

\section{Objectives}

- To study the relationship between Organizational justice with Commitment.

- To study the relationship between Organizational justice with Competence.

- To study the relationship between Organizational justice with Self Motivation.

- To study the relationship between Organizational Justice and Work Commitment, Comp etence and Self Motivation together,

\section{Hypothesis}

- Workplace justice is expected to be significantly related to Commitment.

- Workplace justice is expected to be significantly related to Competence.

- Workplace justice is expected to be significantly related to Self motivation.

- Distributive and Procedural Justice are expected to significantly affect level of work com mitment and competence.

- Interactional and Procedural Justice are expected to significantly affect level of self moti vation.

\section{Locale of Study}

The data for the current study was collected from Amity University Noida campus. The data collection required the facilities to fill in the questionnaires as per the instructions mentioned.

\section{Sample And Participants}

- Sample : 80

- Location: Delhi/NCR

- Occupation: Teaching/Administration

- Experience: At least one year

\section{Research Design And Variable}

The research design for the current study on Organizational Justice In Relation to Commitment, Competence and Self Motivation, would be Ex Post Facto.

Ex post facto is a type of research design and is generally used in those fields where an individual does reanalysis of the studies already into existence with the purpose of coming up with a new finding. 


\section{Organizational Justice in Relation to Competence, Commitment and Self Motivation}

In Ex Post Facto the Cost-Effect relationship of the dependant and Independent variables are studied.

\section{Data And Statistical Analysis}

Mean: The statistical mean refers to the mean or average that is used to derive the central tendency of the given data.

Standard Deviation: The Standard Deviation is a measure of how spreads out numbers are.

Correlation: A correlation describes direction (positive or negative) and degree (strength) of relationship between two variables. The higher the correlation coefficient, the stronger the relationship.

Table

\begin{tabular}{|l|l|}
\hline Dependent Variable & Independent Variables \\
\hline Organizational Justice & Commitment \\
\hline & Competence \\
\hline & Self Motivation \\
\hline
\end{tabular}

Tool And Instrumentation

\begin{tabular}{|l|l|l|l|l|}
\hline S.No, & $\begin{array}{l}\text { Name of the } \\
\text { Psychological Tool }\end{array}$ & $\begin{array}{l}\text { Developed } \\
\text { By }\end{array}$ & Year & No. of Items \\
\hline 1. & Organizational Justice & J.A Colquitt & 2001 & 20 \\
\hline 2. & CCSM & Amity University, Noida & 2013 & 24 \\
\hline
\end{tabular}

\section{Description of the Tools}

\section{Colquitt's Organizational Justice Measure :}

This tool was developed by J.A Colquitt in the year 2001 to measure the level of justice prevailing in an organization. The Colquitt's Organizational Justice Measure scale is based on likert scale ranging from 1 (agree to small extent) to 5 (agreed to large extent), comprising of 20 statements to be answered) accordingly.

\section{CCSM- Commitment, Competence and Self Motivation :}

This tool was developed by Amity University, Noida in the year 2013 with the purpose of measuring the level of commitment, competence and self motivation existing among facilities working in a particular organization. This scale comprises of 24 statements, 8 statements for 
measuring commitment, 8 statements for competence and 8 statements for measuring self motivation.

\section{RESULTS AND ANALYSIS}

Table 1: Comparison of Mean and Standard Deviation scores among Organizational Justice, Competence, Commitment, Self Motivation And CCSM

\begin{tabular}{|c|c|c|c|c|c|c|c|c|c|}
\hline \multirow{2}{*}{\multicolumn{2}{|c|}{$\begin{array}{c}\text { Independent } \\
\text { Variable }\end{array}$}} & \multicolumn{8}{|c|}{ Dependent Variables } \\
\hline & & \multicolumn{2}{|c|}{ Competence } & \multicolumn{2}{|c|}{ Commitment } & \multicolumn{2}{|c|}{ Self Motivation } & \multicolumn{2}{|c|}{ CCSM } \\
\hline Mean & SD & Mean & SD & Mean & SD & Mean & SD & Mean & SD \\
\hline 63.95 & 13.60 & 61.05 & 8.20 & 60.19 & 8.41 & 60.81 & 6.96 & 183.71 & 25.63 \\
\hline
\end{tabular}

Table 1. Shows the comparison among Mean and Standard Deviation scores of Organizational Justice, Competence, Commitment and Self Motivation. There exists a slight difference among the Mean scores of Organizational Justice in comparison to Competence, Commitment and Self Motivation, while there exist a significant difference among the Mean scores of Organizational Justice in comparison to CCSM in total.

The given table also shows that there exists significant level of difference among the Standard Deviation scores of Organizational Justice in comparison to Competence, Commitment, Self Motivation and CCSM when taken into consideration in total.

Graph1: Shows the Mean of Organizational Justice, Competence, Commitment, Self Motivation and CCSM

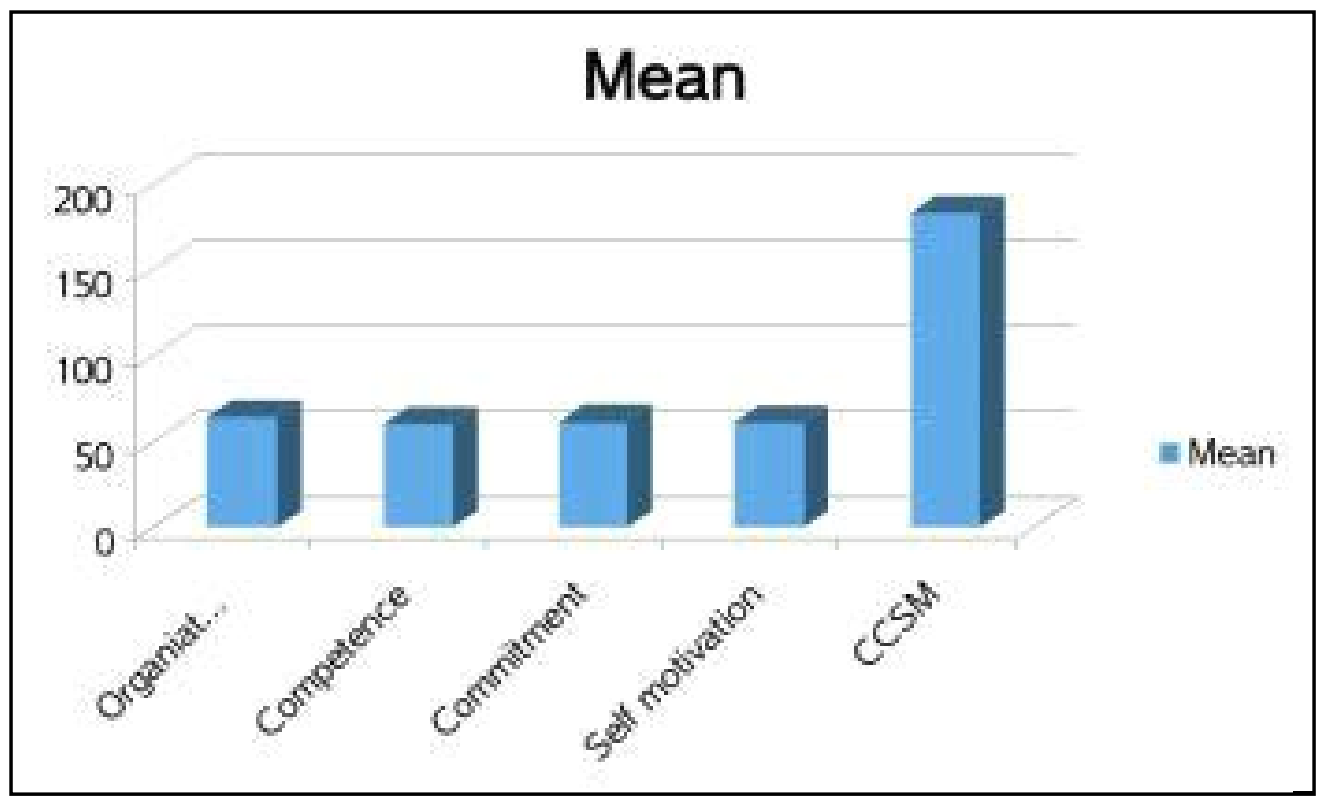




\section{DISCUSSION AND CONCLUSION}

The present study aimed to study the relationship between Organizational Justice and Competence, Commitment and Self Motivation. The sample for the study comprised of 80 facilities working in various departments of the concerned university. Mean, Standard Deviation and Correlation scores were calculated in order to study the significant relationship existing between Organizational Justice as an independent variable and Competence, Commitment and Self Motivation as dependant variables.

Organizational justice has been explained as the level of fair treatment and work environment existing within the organization and perceived by its employees. It has said to have been divided into four areas namely, distributive justice, procedural justice, informational justice and interactional justice. The questionnaire used for the analysis of organizational justice is that of Colquitt's Organizational Justice Measure Scale. It measures and analyses the level of justice by calculating the four areas of justice namely, distributive justice relating to distribution of resources, procedural justice relating to the right of the employee to have a say in the various concerned processes executed within the organization, informational justice relating to how well and timely various information are conveyed and interactional justice relating to how healthy interpersonal relationships does an employee shares with his colleagues, all individually. The tool comprises of 20 statements based on likert scale.

For studying the level of Commitment, Competence and Self Motivation, Amity University's CCSM Scale has been used. This scale helps in calculating and analyzing the level Competence, Commitment and Self Motivation among individual employees both separately as well as together. This scale comprises of 24 statements to be scored within a range of 1 to 10 . Each section of Competence, Commitment and Self Motivation consists of 8 statements respectively.

The current study and analysis show that there exists a positive correlation among Organizational Justice as an independent variable, and Competence, Commitment and Self Motivation as dependent variables. This means that with an increase in the level of Organizational Justice the level of Competence, Commitment and Self Motivation among the employees of the organization will increase significantly, while with a decrease in the level of Organizational Justice the level of Competence, Commitment and Self Motivation will decrease significantly. Also scores of Commitment were found to be highly and equally correlated with Organizational Justice as CCSM's score of correlation. This shows that with an increase or decrease in the level of Organizational Justice the level of Commitment will increase it decrease much in the same proportion as CCSM (total scores of Competence, Commitment and Self Motivation).

Previous studies in the current field of organizational justice in relation to commitment, competence and self motivation also have shown similar results. But the significant increase as well as decrease in the level of commitment in relation to organizational justice, sharing equal tendencies of such changes in scores with that of CCSM has been a new finding. 


\section{Organizational Justice in Relation to Competence, Commitment and Self Motivation}

Commitment is said to increase or decrease as per the level of increase or decrease in organizational justice as previous studies has also shown that, an employee will put in his efforts to add on to the overall productivity of an organization only if he perceives the level of justice prevailing within the organization to be fair enough. Though all three variables namely, competence, commitment and self motivation are interrelated to one another, changes in one causing changes in the other, but commitment can still be considered to play a slightly dominant role in the influencing the overall level of CCSM.

This inference can be taken out from the current study done with a purpose of studying the relationship between Organizational Justice and Competence, Commitment and Self Motivation.

The facilities of the university are expected to inculcate best of knowledge and finest of wisdom among their students. They are considered to be highly responsible for both effective performance of the students at a micro level and functioning of the university at the macro level. Studies done in 1993 by Moorman, Nieoff and Organ showed that the level of job satisfaction and commitment of an individual working within an organization is affected by the prevailing level of justice to a great extent. The organization citizenship behavior which gets inculcated in an individual employee depends highly on the type of treatment that is received and the justified work procedures that they made to get involved in.

Similar study done by Sussana Baldwin in 2006 showed that for sound managerial practices the satisfaction of employee's job needs has to fall under the prior concern of the organization. The managerial practices refers basically to the various processes that are executed with some defined purposes, such processes has to take into consideration the say and consent of the employees working for it. A study done in year 2011 by Choudhury, Philip and Kumar showed that employees acts as an asset to the organization. The effectiveness of the functioning of an organization depends highly on how the employees perform, therefore their job satisfaction level and self motivation level turns out to be crucial factors in determining an organization's level of productivity.

With such responsibilities and expectations comes the requirement of facilities to perform and render effective results as well. With low level of commitment, competence and self motivation the level of performance effectiveness will be considerably low. And since the present study shows a significant relationship between Organizational Justice and Competence, Commitment and Self Motivation, it has to be the prior motive of the university to grill out the flaws from the root level responsible for the low or average level if justice prevailing within the organization and strengthen as well as stretch it to greater heights. More the level of organizational justice more will be the level of work satisfaction among the facilities and thus their competence, commitment and self motivation level would also increase.

Table 1 showed the significant difference among the Mean and Standard Deviation scores of Organizational Justice and Competence, Commitment and Self Motivation as well as CCSM in comparison to each other. Commitment showing a significantly higher difference in the level of 


\section{Organizational Justice in Relation to Competence, Commitment and Self Motivation}

scores as compared to the other two dependent variables with that of organizational justice's scores.

Table 2 showed that organizational justice is positively correlated with commitment, competence and self motivation individually and CCSM in total. With scores of commitment being more positively related to organizational justice like that of CCSM, both having a score of 0.77.

Commitment refers to the extent to which an individual is willing to put in the best of his or her efforts to make a given task successful. Competence relates to an individual's awareness regarding his or her own potential and how well can he or she manage to put in the best of the potential level in order to reap better results. Self Motivation relates to an individual's own level of willingness to work for the better and thrive for success.

Commitment among the facilities was analyzed based on the following factors mentioned in the questionnaire:

- Functional Competence further analyzed on the basis of Knowledge Acquisition Knowledge Creation Knowledge Transfer and Academic Management.

- Peripheral Competence further analyzed on the basis of Positive Attitude, Interpersonal Communication, Mentoring and Team Work.

- The level of Competence was measured among the facilities based on the following factors mentioned in the questionnaire:

- Affective Commitment further analyzed on the basis of Initiative, Openness and Transparency, Emotional Engagement and Purpose Engagement.

- Work Commitment further analyzed on the basis of Job Effectiveness, Adaptability, Dedication and Result Orientation.

- The level of Self Motivation among facilities were analyzed based on the following factors mentioned in the questionnaire :

- Self Leadership was further analyzed on the basis of Solution Seeking Attitude, Self Sufficiency, Social Responsibility and Working for greater good.

- Self Governance was further analyzed on the basis of Goal Directed, Integrity, Resilience and Achievement Orientation.

In the given study data were collected among the facilities of various departments within the campus of the university and the level of organizational justice based on the perception of the facilities and the level of CCSM among them in relation to the justice levels perceived were made. It was found that due to average level of justice prevailing within the organization the level of CCSM among the facilities were also average. However in accordance to the main aim of conducting this study we can say that organizational justice any day positively correlates with CCSM, commitment being comparatively higher in independent correlation compared to other two factors. 


\section{Organizational Justice in Relation to Competence, Commitment and Self Motivation}

Hence the Hypothesis is supported that Organizational Justice shares a direct and positive correlation with Commitment, Competence and Self Motivation. With an increase in the level of organizational justice the level of commitment among facilities will increase and with a decrease in the level of justice the level of commitment among facilities will decrease.

Similarly with an increase in the level of organizational justice the level of competence among facilities will increase and with a decrease in the level of organizational justice the level of competence will decrease.

Also with an increase in the level of organizational justice the level of self motivation among facilities will increase and with a decrease in the level of organizational justice the level of self motivation will decrease.

Finally we can state that with an increase in the level of organizational justice the level of CCSM among the facilities will increase and with a decrease in the level of organizational justice the level of CCSM will decrease.

Also we can state that with an increase in the level of organizational justice the level of Commitment will rise higher at an individual level compared to the other two variables, thus contributing higher scores to the overall CCSM compared to Competence and Self Motivation

\section{REFERENCES}

Abhishek kumar Totawar and Ranjeet Nambudiri.2014.How does organizational justice affect job satisfaction and organizational commitment?

Bakshi, Kumar and Rani.2009.Organizational Justice Perceptions as Predictor of Job Satisfaction and Organization Commitment.

Bard Kuvaas.2006.Work performance, affective commitment, and work motivation: the roles of pay administration and pay level. Journal of Organizational Behavior Volume 27, issue 3.

Bernad. C. Reimann. 2013.Organizational Competence as a Predictor of Long Run Survival and Growth.

Choong Kwai Fatt, Edward Wong Sek Khin and Tioh Ngee Heng .2010.The Impact of Organizational Justice on Employee's Job Satisfaction: The Malaysian Companies Perspective.

Christopher.L.Martini. 1996.The Role of Justice Judgments in Explaining the Relationship between Job Satisfaction and OrganizationaCommitment. Louisiana State University, Shreveport, Louisiana State University, Baton Rouge.

Cindy P. Zapata-Phelan Jason A. Colquitt Brent A. ScottBeth Livingston.2008.Procedural justice, interactional justice, and task performance: The mediating role of intrinsic motivation.

Cropanzano, R., \& Rupp, D. E. (2003). An overview of organizational justice: Implications for work motivation. In L. W. Porter, G. Bigley, \& R. M. Steers (Eds.), Motivation and work behavior (7th Ed.). New York: McGraw-Hill Irwin. 


\section{Organizational Justice in Relation to Competence, Commitment and Self Motivation}

Elaine Farndale. 2010.High Commitment Performance Management: The Roles of Justice and Trust.

Fariba Rafei-Dehkordi, Sardar Mohammadi and Mozafar Yektayar.2013Relationship of organizational justice and organizational commitment of the staff in general directorate of youth and sports in Chahar Mahal Va Bakhtiari Province.

G. C. W. Gim and N. Mat Desa year.2014.The Impact of Distributive Justice, Procedural Justice, and Affective Commitment on Turnover Intention among Public and Private Sector Employees in Malaysia.

Ghorbanalizadeh, Safania and Tayabi.2012.Impact of Organizational Justice Perceptions on Job Satisfaction and Organizational Commitment: the Iran's Ministry of Sport Perspective.Australian Journal of Basic and Applied Sciences 01/2012; 6:179-188.

Hyun-Hung Lee. (2004). "The role of competence-based trust and organizational identification in continuous improvement", Journal of Managerial Psychology, Vol. 19 Iss: 6, pp.623 639.

Jeongkoo Yoon and Shaner.2002.A Dual Process Model of Organizational Commitment Job Satisfaction and Organizational Support.

Kanwal Raza, Nosheen Adnan Rana, Mehwish Qadir, Adnan Masood Rana.2013. Relationship Between Distributive, Procedural Justice and Organizational Commitment: An Empirical Analysis on Public Sector of Pakistan.

Klender and Deller.2009. Measuring the perceived impact of Organizational Justice on commitment on ISFAHAN municipality.

Lembert, Hogan and Griffin.2007.Association Between Distributive and Procedural Justice and Life Satisfaction Among Correctional Staff.

Lemons and Jones.2001.Procedural justice in promotion decisions: using perceptions of fairness to build employee commitment.DOI: 10.1108/02683940110391517

Lowe, Stephen and Vodanovich.1995.A field study of distributive and procedural justice as predictors of satisfaction and organizational commitment. Journal of Business and Psychology. Fall 1995, Volume 10, Issue 1, pp 99-114

Martha. C. Andrew, University of Carolina Wimlington, K. Michele Kacmar, University of Alabama, Gerald .L. Blakely.2008.West Virginia University and Neil. S. Bucklew, West Virginia University.

Martin and Bennett.(1996). An Empirical Study of the Organization.

Neetu Choudhry, P. J. Philip, Rajender Kumar.2014.Impactst of Organizational Justice on Organizational Effectiveness .

Ponnu, C.H; Chuah, C.C.2010.Organizational commitment, organizational justice and employee turnover in Malaysia. African Journal of Business Management, 4 (13). pp. 2676-2692.

R.Ficher. 1997.Rewarding Employee Loyalty : An Organizational Justice Approach.

Rai.2013, The relationship between organizational justice and organizational commitment from the view of administrative and supportive personnel in Teaching Hospitals of Ahvaz Jundishapur University of Medical Sciences. 


\section{Organizational Justice in Relation to Competence, Commitment and Self Motivation}

Rhoades, Linda; Eisenberger, Robert; Armeli, Stephen.2001.Affective commitment to the organization: The contribution of perceived organizational support..Journal of Applied Psychology, Vol 86(5), Oct 2001, 825-836.http://dx.doi.org/10.1037/0021-9010.86.5.825.

Robert H. Moorman, Brian P. Niehoff, Dennis W. Organ.1993.Treating employees fairly and organizational citizenship behavior: Sorting the effects of job satisfaction, organizational commitment, and procedural justice. Volume 6, Issue 3, pp 209-225.

Sussana Baldwin. 2006. Organizational Justice. http://www.employment-studies.co.uk

Tang, Thomas Li-Ping; Sarsfield-Baldwin, Linda J.1996. Distributive and Procedural Justice as Related to Satisfaction and Commitment.

Thorn.2010.Perceptions of organizational justice, job satisfaction, and organizational commitment in intercollegiate athletics.

Tremblay, Sire and Balkin. 2000. The Role of Organizational Justice in Pay and Employee Benefit Satisfaction, and its Effects on Work Attitudes.doi: 10.1177/1059601100253004 Group Organization Management. 